\title{
Cerebral Convexity
}

National Cancer Institute

\section{Source}

National Cancer Institute. Cerebral Convexity. NCI Thesaurus. Code C129428.

Area within the sulci of the brain, usually anterior to the rolandic fissure. 